\title{
Teor de zinco, cádmio e chumbo em plantas de arroz em solos incubados com resíduo siderúrgico
}

\author{
André F. M. de Andrade ${ }^{1}$, Nelson M. B. do Amaral Sobrinho ${ }^{2} \&$ Nelson Mazur ${ }^{2}$
}

\begin{abstract}
RESUMO
Os efeitos da aplicação de resíduo siderúrgico, proveniente da concentração de Zn em lama de altos fornos siderúrgicos, como fonte de $\mathrm{Zn}$ às plantas de arroz e a toxicidade de $\mathrm{Cd}$ e $\mathrm{Pb}$ no resíduo, foram avaliados em experimento. 0 material de solo usado proveio do horizonte superficial dos solos Latossolo Vermelho Amarelo (LVA); N eossolo Flúvico (RU) e Argissolo Vermelho Amarelo (PVA), coletados no município de Pinheiral, Estado do Rio de Janeiro; utilizou se a variedade de arroz (O ryza sativa L.) BRS Curinga. As plantas foram coletadas aos 145 dias após a semeadura; aquelas crescidas no Neossolo Flúvico apresentaram a maior produção de matéria seca e a maior acumulação de zinco, mas a menor de cádmio, enquanto as desenvolvidas no Argissolo Vermelho Amarelo indicaram a menor produção de matéria seca, menor acumulação de zinco, mas maior de chumbo e de cádmio. 0 extrator DTPA foi alvo de correlações el evadas e significativas com as concentrações de chumbo, cádmio e zinco, nas raízes e na parte aérea e, com a quantidade acumulada nas plantas, mostrando se bom indicador da biodisponibilidade desses três metais. Pelas características apresentadas nos solos estudados e pelas concentrações fitotóxicas do chumbo e do cádmio encontradas nas plantas desenvolvidas no PVA, não é recomendável a util ização desse resíduo como fonte de zinco para a cultura do arroz.
\end{abstract}

Palavras-chave: metais pesados, poluição, reciclagem, 0 ryza sativa L

\section{Contents of zinc, cadmium and lead in rice plants in soils incubated with slag}

\begin{abstract}
The effects of the application of slag, from the concentration of $\mathrm{Zn}$ in the mud of steel slag, as a source of $\mathrm{Zn}$ for rice plants and the toxicity of $\mathrm{Cd}$ and $\mathrm{Pb}$ in the residue were studied in a greenhouse during the period from April 2005 to March 2006. The material used came from the surface horizon of a Red Yellow Oxisol (LVA); Fluvic Entisol (RU) and Red Yellow ultisol (PVA), collected in the municipality of Pinheiral, in the State of Rio de Janeiro. The variety of rice (O ryza sativa L.) BRS Joker was used. Plants were harvested at 145 days after sowing; those grown in Fluvic Entisol had the highest dry matter production and higher zinc accumulation, but smaller accumulation of cadmium, while the ones in the Typic soil showed the lowest dry matter production, lower accumulation of zinc, but higher lead and cadmium accumulation. The DTPA extractor was subjected to high and significant correlations with the concentrations of lead, cadmium and zinc in roots and shoots and, with the total amount accumulated in plants, showed as a good indicator of the bioavailability of these three metals. According to the characteristics presented in the soils studied and the phytotoxic concentrations of lead and cadmium found in plants grown in PVA, the use of this residue as a source of zinc for rice cultivation is not recommended.
\end{abstract}

Key words: heavy metals, pollution, recycling 


\section{INTRODUÇÃO}

O elevado volume de resíduos gerados na siderurgia faz com que esse tipo de atividade industrial se mantenha em permanente busca de destinos e, como meta, uma agressão ambiental menor com pouco dispêndio de recursos (Lombi et al., 2002; Andrade et al., 2008). A geração anual de aço no mundo foi de 1,13 bilhão de toneladas no ano de 2005 enquanto no Brasil foi de 31 milhões de toneladas (IBS, 2006). O índice de geração é de $700 \mathrm{~kg}$ de resíduo por tonelada de aço o que perfaz cerca de $20 \mathrm{mi}$ lhões de toneladas de resíduos por ano (IISI, 1994). Entre os destinos dados aos resíduos siderúrgicos estão à reciclagem; a venda, pavimentação, uso agrícola e o menos interessante, a disposição em aterros (Andrade et al., 2008).

Muitas indústrias têm produzido resíduos ricos em zinco passíveis de serem utilizados como fertilizante na agricultura havendo, porém, a necessidade de se intensificar uma pesquisa integrada de aproveitamento dos resíduos industriais, como maneira viável de minimizar os impactos causados ao meio ambiente por esses materiais, que podem adicionar ao solo metais pesados potencialmente tóxicos, como o chumbo e o cádmio (Carneiro et al., 2002; Castaldi \& Melis, 2004; Gichner et al., 2006; Andrade et al., 2008).

Segundo Oliveira et al. (2005), admite se que nos solos brasileiros, devido à grande frequência de deficiência de zinco em muitas culturas, a disponibilidade do nutriente seja pequena. Barbosa Filho et al. (1990; 1992), citam que o zinco é o micronutriente cuja deficiência mais tem limitado a produção de arroz de sequeiro no Brasil e que pequenas quantidades $\left(35 \mathrm{~kg} \mathrm{ha}^{1}\right.$ ) tem sido suficiente para a correção desse elemento no solo, causando durante mais de 4 anos efeito residual.

O resíduo siderúrgico proveniente da concentração de lama de altos fornos siderúrgicos apresenta elevadas concentrações de zinco $(3,1 \%)$, o que originou a proposta de utilizá lo como fonte desse micronutriente para as plantas, uso que, além da crescente demanda pelo mercado, permitiria um destino mais adequado ao resíduo; entretanto, outros metais pesados são normalmente detectados no processo siderúrgico, entre eles o chumbo e o cádmio.

Objetivou-se neste trabalho avaliar se o resíduo Concentrado de Lama dos Altos Fornos da CSN, disponibiliza zinco para o suprimento adequado da cultura de arroz em diferentes solos e, também, se provoca toxicidade às plantas por cádmio e chumbo.

\section{MATERIAL E MÉTODOS}

O resíduo foi analisado conforme legislação ambiental vigente, segundo a Norma 10004 (ABNT, 2004) para sua classificação e como fonte de zinco às plantas. As concentrações de cádmio e chumbo no ensaio de lixiviação foram de 0,74 e $12,8 \mathrm{mg} \mathrm{L}^{1}$, respectivamente, acima, portanto, do limite máximo permitido de 0,5 e 1,0 $\mathrm{mg} \mathrm{L}^{1}$; desta forma, o resíduo foi classificado como Classe I, de acordo com a mesma Norma 10004 da ABNT. Os valores de $\mathrm{Zn} ; \mathrm{Cd} ; \mathrm{Pb} ; \mathrm{Fe}$; Mn; Cu; Cr e Al no resíduo, foram de: 31060; 500; 15960; 147200; 6150; 50; 10 e $14380 \mathrm{mg} \mathrm{kg}^{1}$, respectivamente. Amostras de terra de três solos, um Latossolo Vermelho Amarelo (LVA), Argissolo Vermelho Amarelo (PVA) e Neossolo Flúvico (RU) no município de Pinheiral, RJ, foram coletadas na profundidade de $020 \mathrm{~cm}$. Os atributos físicos e químicos (Tabela 1) foram determinados conforme as metodologias sugeridas por EMBRAPA (1997).

O experimento foi conduzido em casa de vegetação do campus da Universidade Federal Rural do Rio de Janeiro (UFRRJ), município de Seropédica, RJ ( $22^{\circ} 47^{\prime}$ de latitude sul e $43^{\circ} 40^{\prime}$ de longitude oeste), as amostras de solo após secadas ao ar e passadas em tamis de malha de 4,0 mm, e incorporadas a $4 \mathrm{~kg}$ de cada solo com o resíduo e então acondicionados em vasilhames plásticos de $5 \mathrm{~L}$, sem drenagem.

Utilizaram-se quatro doses de resíduos (base seca) correspondentes a: $94 ; 281 ; 844$ e $2531 \mathrm{~kg} \mathrm{ha}^{1}$, que continham 3; 9; 27 e $81 \mathrm{~kg}$ Zn ha ${ }^{1} ; 1,6 ; 4,8 ; 14,4$ e 43,2 kg Pb ha ${ }^{1}$, e 0,05; 0,15; 0,45 e $1,35 \mathrm{~kg} \mathrm{Cd} \mathrm{ha}{ }^{1}$. Os valores contidos a partir da segunda dose já apresentavam teores de zinco próximos às necessidades de algumas culturas e na maior dose do resíduo o valor de zinco já é considerado fitotóxico para certas culturas (Fageria, 2000). Utilizou se o arroz (Oryza sativa L.) variedade BRS Curinga por ser responsiva à adição de zinco (Fageria, 2000) em unidades experimentais que seguiram o delineamento de blocos ao acaso em esquema fatorial $3 \times 5 \times 4$.

Após a incubação do resíduo com cada solo, durante 60 dias, fez se a extração simples com DTPA $0,005 \mathrm{~mol} \mathrm{~L}^{1}$ para avaliar a biodisponibilidade de zinco, cádmio e chumbo. $\mathrm{O}$ preparo da solução consistiu em se dissolver $149,2 \mathrm{~mL}$ de TEA, $19,67 \mathrm{~g}$ de DTPA e $14,7 \mathrm{~g}$ de $\mathrm{CaCl}_{2} .2 \mathrm{H}_{2} \mathrm{O}$ em aproximadamente 2,0 L de água deionizada; após a dissolução do DTPA ele foi diluído para $9 \mathrm{~L}, \mathrm{o} \mathrm{pH}$ foi ajustado para 7,3 $\pm 0,05$ com $\mathrm{HCl} 1: 1$; em seguida, o volume foi completado para $10 \mathrm{~L}$ com água deionizada. A extração consistiu em se agitar, durante 2 h, 15 g do solo com $30 \mathrm{~mL}$ da solução de DTPA (Lindsay \& Norvell, 1978).

Fez-se a semeadura com arroz mantendo se 4 plantas de arroz por unidade experimental. Durante o período de incuba-

Tabela 1. Características químicas e físicas das amostras dos solos utilizadas

\begin{tabular}{|c|c|c|c|c|c|c|c|c|c|c|c|c|c|c|c|c|c|c|c|}
\hline \multirow{2}{*}{ Solo } & \multirow{2}{*}{$\begin{array}{l}\text { Prof. } \\
(\mathrm{cm})\end{array}$} & \multirow{2}{*}{$\mathrm{pH}$} & $\mathrm{Ca}^{2}$ & $\mathrm{Mg}^{2+}$ & $\mathrm{H}+\mathrm{Al}$ & $\mathbf{A l}^{3+}$ & \multirow{2}{*}{$\mathbf{S}(\%)$} & \multirow{2}{*}{$\mathrm{T}(\%)$} & \multirow{2}{*}{$V(\%)$} & $\mathbf{P}$ & $K$ & \multirow{2}{*}{$\underset{\left(g^{~ k g-1}\right)}{C}$} & $\mathrm{Zn}$ & $\mathrm{Cd}$ & $\mathbf{P b}$ & \multirow{2}{*}{$\begin{array}{c}\text { Densidade } \\
\left(\mathrm{g} \mathrm{cm}^{3}\right)\end{array}$} & \multicolumn{3}{|c|}{ Granulometria $\left(\mathrm{g} \mathrm{kg}^{-1}\right)$} \\
\hline & & & \multicolumn{4}{|c|}{$\mathrm{cmol}_{\mathrm{c}}\left(\mathrm{dm}^{3}\right)^{-1}$} & & & & \multicolumn{2}{|c|}{$\mathrm{mg} \mathrm{kg}^{-1}$} & & & $\mathrm{mg} \mathrm{kg}^{-1}$ & & & Areia & Silte & Argila \\
\hline LVA & $0-20$ & 5,9 & 1,2 & 1,3 & 7,1 & 0,0 & 2,6 & 9,6 & 26 & 5 & 56 & 22,5 & 15,8 & nd & 12 & 1,03 & 470 & 100 & 430 \\
\hline PVA & $30-50$ & 4,5 & 0,6 & 0,1 & 5,6 & 1,9 & 0,7 & 7,3 & 10 & 1 & 11 & 7,6 & 9,9 & nd & 13 & 1,18 & 370 & 60 & 570 \\
\hline RU & $0-20$ & 5,8 & 3,2 & 2,4 & 3,3 & 0,0 & 6,0 & 9,3 & 74 & 52 & 136 & 8,9 & 79,0 & nd & 21,7 & 1,14 & 658 & 166 & 176 \\
\hline
\end{tabular}

pH em água (1:2,5); Ca e Mg, H+Al extraídos em KCl 1N; Al extraído em acetato de cálcio $1 \mathrm{~N}$ a pH 7,0: $\mathrm{P}$ - extraído com solução Carolina do Norte, K - extraído com dicromato de potássio $1 \mathrm{~N}$; C - Walkley Black 
ção a umidade foi mantida a $80 \%$ da capacidade de campo, através da diferença de pesagens dos potes. Os nutrientes e suas dosagens aplicadas estão indicadas na Tabela 2. Ao final do experimento foram colhidas, separadamente, as folhas, colmos e raízes, lavadas em água de torneira e em água deionizada, após a secagem em estufa com circulação de ar até atingirem massa constante. Cada material foi triturado em moinho tipo Willey com malha de $2 \mathrm{~mm}$. Utilizou se o procedimento metodológico de digestão proposto por Tedesco et al. (1995) com ácido nítrico (65\%) e ácido perclórico (85\%) na proporção 2:1 com $5 \mathrm{~mL}$ para cada $0,250 \mathrm{~g}$ de amostra analisada. No extrato obtido foram determinados os teores zinco, chumbo e cádmio por espectrofotometria de absorção atômica em aparelho Varian AA600 com LD $\left(\mathrm{mg} \mathrm{kg}^{-1}\right)$ de 0,12 para $\mathrm{Cd}, 0,10$ para $\mathrm{Pb}$ e 0,20 para $\mathrm{Zn}$ e LQ $\left(\mathrm{mg} \mathrm{kg}^{-1}\right)$ de 0,5 para $\mathrm{Cd}$, 0,5 para $\mathrm{Pb}$ e 0,7 para $\mathrm{Zn}$.

Tabela 2. Quantidade adicionada ( $\mathrm{mg} \mathrm{kg}^{-1}$ solo) e fonte dos nutrientes aplicados

\begin{tabular}{ccccc}
\hline \multirow{2}{*}{ Nutriente } & \multicolumn{2}{c}{ 1a dose } & \multicolumn{2}{c}{ 2a dose } \\
\cline { 2 - 5 } & Quantidade & Fonte & Quantidade & Fonte \\
$\mathrm{N}$ & 295 & $\mathrm{NH} 4 \mathrm{NO} 03$ & 100 & $\mathrm{NH} 4 \mathrm{NO3}$ \\
$\mathrm{P}$ & 370 & $\mathrm{KH} 2 \mathrm{PO4}$ & - & - \\
$\mathrm{K}$ & 84 & $\mathrm{KH} 2 \mathrm{PO} 0$ & 84 & $\mathrm{KCl}$ \\
$\mathrm{Mg}$ & 15 & $\mathrm{MgSO4}$ & 15 & $\mathrm{MgSO4}$ \\
$\mathrm{Ca}$ & - & - & 60 & $\mathrm{CaCl} 2$ \\
\hline
\end{tabular}

* 7 dias antes da semeadura; ** 60 dias após semeadura (emissão floral)

Os resultados foram submetidos a análise de variância, teste de Tukey e regressão polinomial utilizando se o programa SAEG, versão 5.0, desenvolvido por Euclydes (1983).

\section{RESULTADOS E DISCUSSÃO}

A extração de zinco com DTPA aumentou em função da dose aplicada nos três solos (Tabela 3). Verifica se, também, que as concentrações referentes ao Neossolo Fúlvico (RU) são quase o dobro das determinadas nos LVA e PVA.

As maiores extrações de cádmio e chumbo foram registradas no PVA, principalmente nas maiores doses do resíduo aplicado. Conforme (Basta \& McGowen, 2004; Oliveira et al., 2005; Santos et al., 2006; Fadigas et al., 2006), esta maior extração pode ser devida ao menor valor de pH observado neste solo (Tabela 1). Segundo Accioly et al. (2004) e Sposito (2008), a redução de uma unidade de $\mathrm{pH}$ aumenta cerca de 100 vezes a solubilidade do cádmio e do chumbo.

As maiores concentrações de $\mathrm{Zn}$ foram determinadas nas raízes em relação à parte aérea dos três solos estudados (Figura 1). Pelos dados. à espécie utilizada não transferiu zinco das raízes para a parte aérea nem desta para os grãos. Neste sentido, Bonnecarrère et al. (2004) mencionam a tendência do zinco de se acumular nas raízes, sobretudo, quando absorvido em grandes concentrações. Oliveira et al. (2005), também constataram após trabalhar com lodo de esgoto contaminado
Tabela 3. Teor biodisponível de zinco, cádmio e chumbo em função das doses do resíduo e tipo de solo

\begin{tabular}{|c|c|c|c|}
\hline \multirow{2}{*}{$\begin{array}{c}\text { Dose } \\
\text { (kg resíduo ha-1) }^{-1} \text { ) }\end{array}$} & \multicolumn{3}{|c|}{ Solo $\left(\mathrm{mg} \mathrm{kg}^{1}\right)$} \\
\hline & LVA & RU & PVA \\
\hline & \multicolumn{3}{|c|}{ Znco } \\
\hline 0 & $2,50(15,3) * d c B$ & $13,76(17,4) C A$ & $0.90(9,65) \mathrm{dC}$ \\
\hline 94 & $3,20(19,0) C B$ & $14,58(18,11) \mathrm{CA}$ & $1,95(18,0) \mathrm{dB}$ \\
\hline 281 & $4,60(22,0) C B$ & $14,08(16,86) \mathrm{CA}$ & $3,22(23,30) \mathrm{CB}$ \\
\hline 844 & $10,80(36,19) b B$ & $18,16(19,63) b A$ & $6,20(27,17) b C$ \\
\hline \multirow[t]{2}{*}{2531} & $21,00(36,94) a B$ & $44,00(36,82) a A$ & $22,00(44,16) a B$ \\
\hline & \multicolumn{3}{|c|}{ Cádmio } \\
\hline 0 & nd & nd & nd \\
\hline 94 & nd & nd & nd \\
\hline 281 & nd & nd & $0,05 c$ \\
\hline 844 & nd & $0,14(13,2) b A$ & $0,21(24,4) b A$ \\
\hline \multirow[t]{2}{*}{2531} & $0,25(18,5) \mathrm{aB}$ & $0,20(13,24) a B$ & $0,41(31,29) a A$ \\
\hline & \multicolumn{3}{|c|}{ Chumbo } \\
\hline 0 & $1,5(9,3) \mathrm{CA}$ & $1,26(5,8) d B$ & $1,52(11,1) d A$ \\
\hline 94 & $1,5(9,4) C B$ & $1,50(6,6) d B$ & $1,9(13,1) d A$ \\
\hline 281 & $2,36(12,7) b B$ & $2,20(9,1) c B$ & $3,60(22,4) C A$ \\
\hline 844 & $3,60(15,41) b C$ & $5,96(20,6) b B$ & $8,10(38,7) \mathrm{bA}$ \\
\hline 2531 & $12,46(33,0) a A$ & $8,93(20,6) a B$ & $14,10(39,9)$ aA \\
\hline $\begin{array}{l}\text { Valores entre parê } \\
\text { com DTPA; Let } \\
\text { significativamente } \\
\text { Letras maiúsculas }\end{array}$ & s representam & a percentagem d & $\begin{array}{l}\text { do total extraído } \\
\text { as não diferem } \\
\text { de probabilidade; } \\
\text { cativamente pelo }\end{array}$ \\
\hline
\end{tabular}

A.

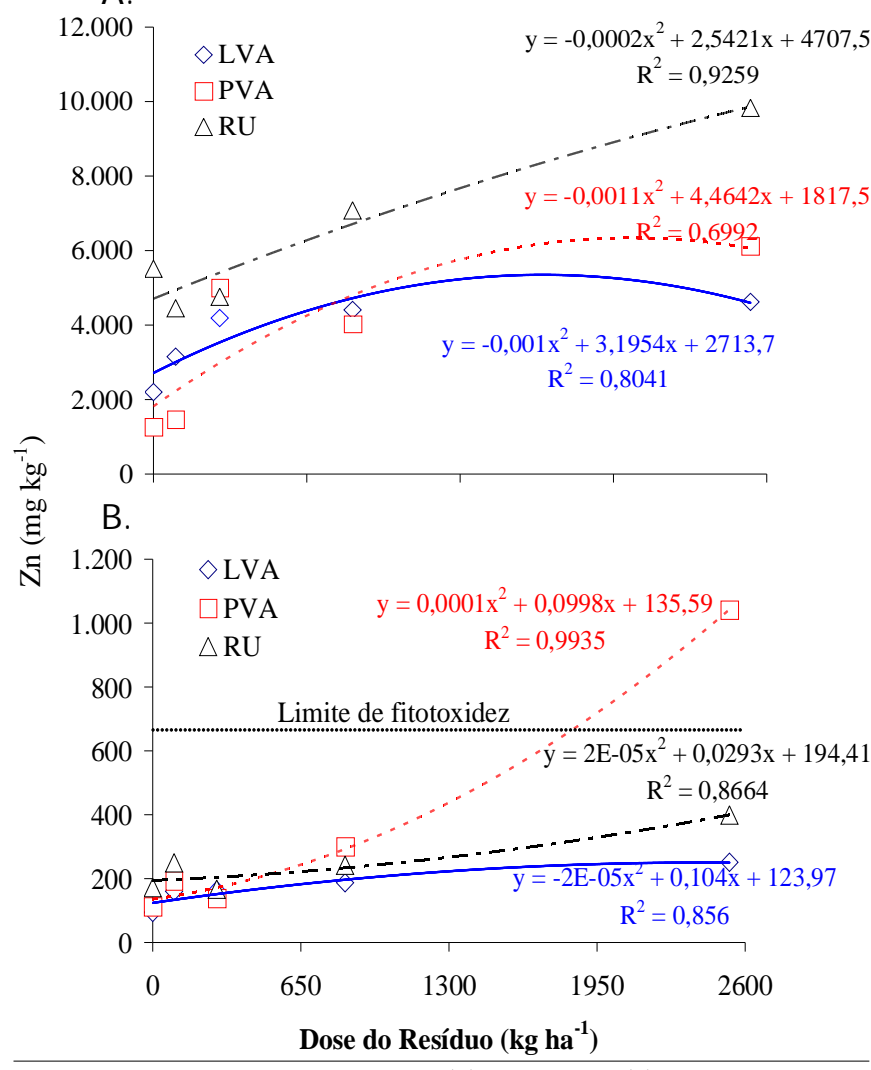

Figura 1. Concentração de zinco na raiz (A) e parte aérea (B) em plantas de arroz (O ryza sativa L.) BRS Curinga cultivadas nos solos LVA; PVA e RU tratados com resíduo siderúrgico 
com zinco, uma translocação menor do zinco da raiz para a parte aérea e grãos de arroz.

A concentração de zinco considerada tóxica na matéria seca foliar de arroz, conforme Fageria (2000), é de $673 \mathrm{mg} \mathrm{kg}^{1}$. A concentração de zinco observada na maior dose nas plantas desenvolvidas no solo PVA, foi de aproximadamente $1000 \mathrm{mg} \mathrm{kg}^{1}$, valor três vezes superior ao das plantas de arroz no LVA e RU (Figura 1B). Essas elevadas concentrações podem ter contribuído para a fitotoxicidade das plantas de arroz, resultando na redução da matéria seca total, como observado na maior dose do resíduo, comparada com os outros dois solos (Figura 2).

As menores concentrações de zinco nas plantas de arroz dos solos LVA e RU podem ter sido resposta da diluição provocada pela maior produção de matéria seca total nas plantas desenvolvidas nesses solos (Figura 2). Referidos resultados podem ser um efeito da maior quantidade de zinco acumulada nas plantas de arroz desenvolvidas no solo RU, o que foi superior ao dobro do acumulado nas plantas do PVA (Figura 3). A maior acumulação de zinco nas plantas de arroz crescidas no RU foi causada pela sua maior biodisponibilidade nesse solo como, inclusive, se verifica na Tabela 3, em que a concentração de zinco extraída com DTPA do solo RU, na maior dose do resíduo aplicado, foi de duas vezes a dos solos LVA e PVA, respectivamente.

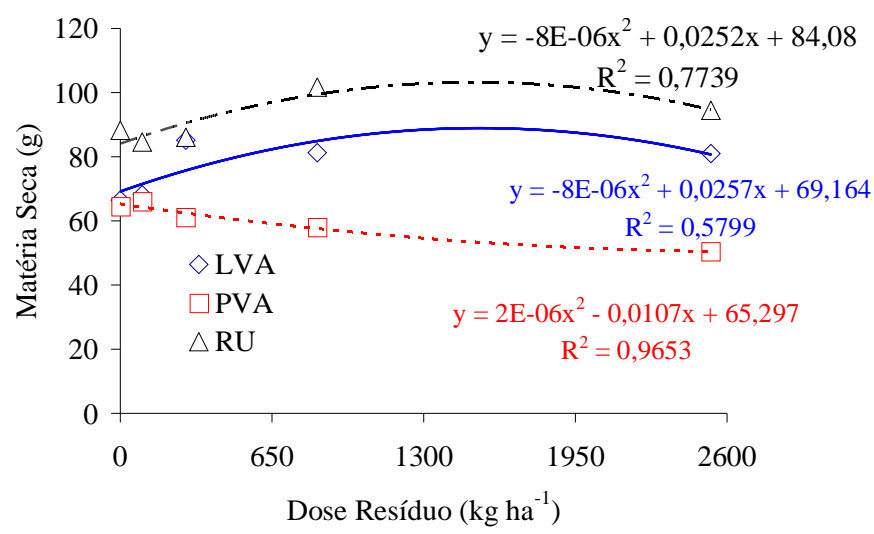

Figura 2. Produção de matéria seca (M S) total (raiz + parte aérea + grão) em plantas de arroz (Oryza sativa L.) BRS Curinga cultivadas nos solos LVA; PVA e RU tratados com resíduo siderúrgico

As concentrações de chumbo nas raízes e parte aérea não apresentaram grande variabilidade entre as plantas desenvolvidas nos solos LVA e RU com o aumento da dose de resíduo aplicado (Figura 4) apesar da maior biomassa nesses solos (Figura 2) e menos chumbo nas plantas (Figura 3), essas duas situações expressam menor biodisponibilidade desse metal nos dois solos (Tabela 3). A solubilidade do chumbo aumenta com a redução do pH (Oliveira et al., 2005; Castaldi et al., 2005) resultando em concentrações mais elevadas desse elemento nas raízes e parte aérea das plantas desenvolvidas sobre o solo PVA (Figura 4), que apresenta menor pH (Tabela 1) e maior biodisponibilidade (Tabela 3). Em geral, a massa de chumbo acumulada nas plantas (Figura 3) também foi mais elevada nesse solo (3 vezes superior ao das plantas do RU e quase 8 vezes maior das plantas do LVA), resposta da sua
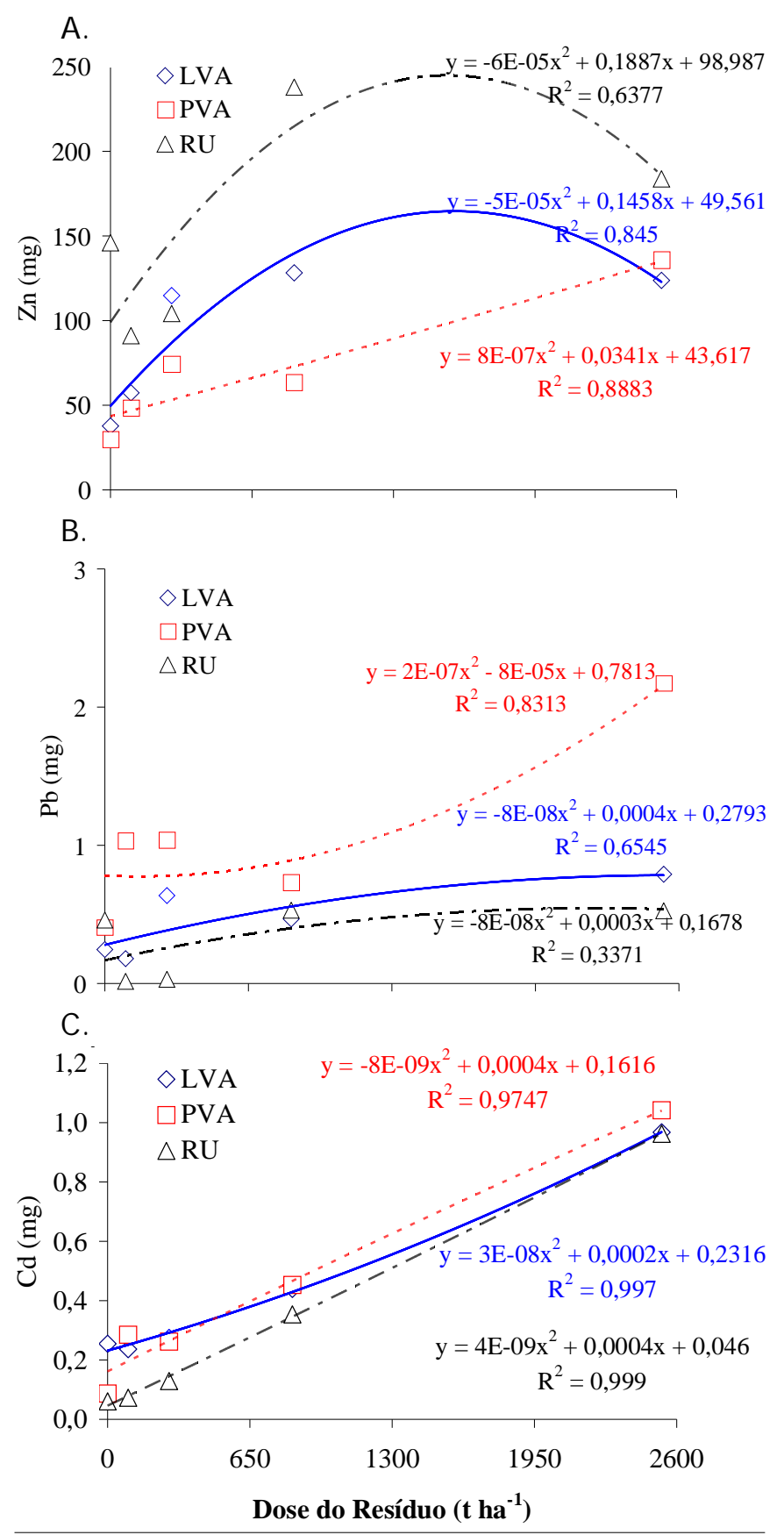

Figura 3. Acumulação de zinco $(A)$; chumbo $(B)$ e cádmio $(C)$ em plantas de arroz cultivadas nos solos LVA; PVA e RU, tratados com resíduo siderúrgico

maior acidez, que resulta em maior biodisponibilidade desse metal no referido solo. Tal acúmulo crescente de chumbo contribuiu para a fitotoxicidade das plantas desenvolvidas no solo PVA, provocando perda da capacidade de produção de matéria seca total das plantas em mais de $20 \%$ (Figura 2). Para Pavlíková et al. (2008) e Fageria (2000), valores de redução da produção em torno de $10 \%$ são admitidos como efeito da fitotoxicidade.

Sharma \& Dubey (2005) e Gupta \& Sinha (2007) mencionam a acentuada redução na produtividade de culturas em solos contaminados com chumbo e o fato de que atributos do solo como pH e capacidade de troca catiônica (CTC) afetam a biodisponibilidade no solos e absorção de chumbo pelas 


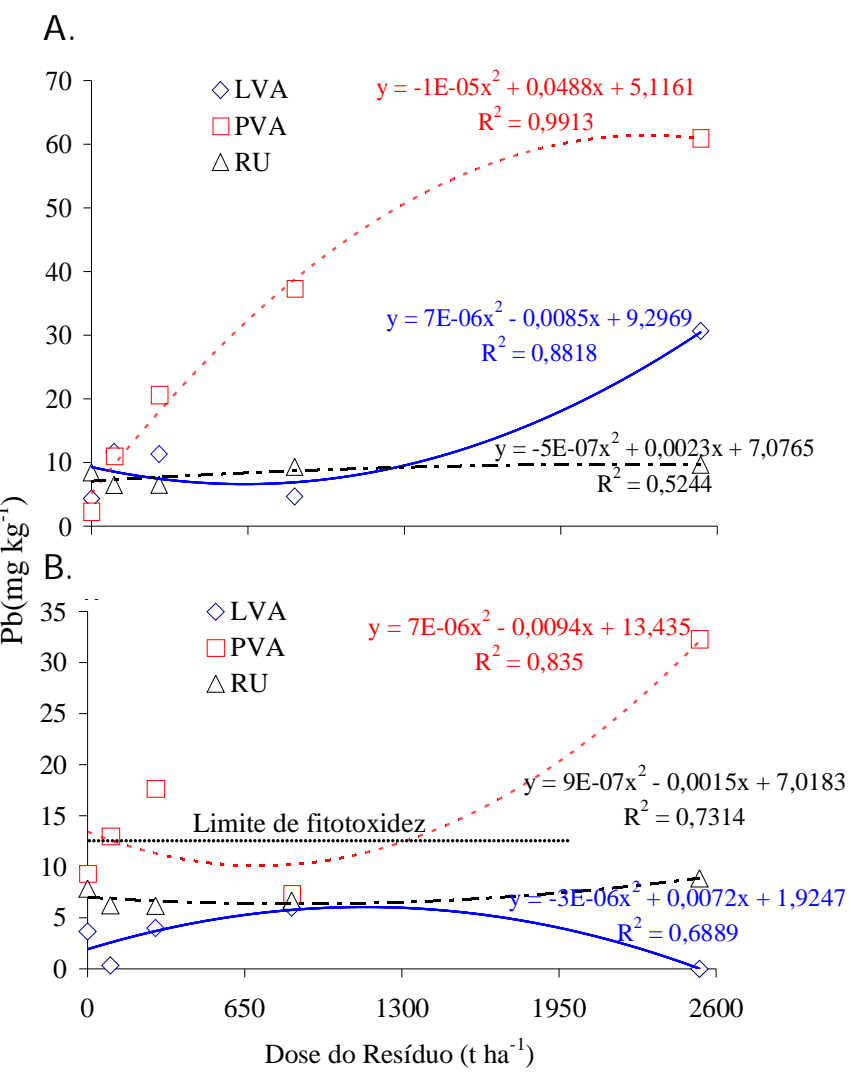

Figura 4. Concentração de chumbo na raiz $(A)$ e parte aérea $(B)$ em plantas de arroz cultivadas nos solos LVA; PVA e RU, tratados com resíduo siderúrgico

plantas. Borges \& Coutinho (2004), e Banat et al. (2005) registraram a diminuição na absorção de $\mathrm{Pb}$ por plantas com o aumento do $\mathrm{pH}$, situação semelhante à observada nos LVA $\mathrm{e}$ RU, e do teor de matéria orgânica, como constatado no LVA. De acordo com os autores, o íon $\mathrm{Pb}^{2+}$ pode formar complexos químicos com compostos húmicos enquanto a calagem eleva o pH do solo, resultando na capacidade da matéria orgânica em complexar o metal pesado.

A maior produção de biomassa das plantas nos solos LVA e RU, comparada com a do PVA, indica a melhor condição fisiológica das plantas nesses solos, em que, conforme Alloway (1995) e Castaldi \& Melis (2004) o chumbo se precipita nas paredes das células das raízes reduzindo sua translocação para a parte aérea e, consequentemente, menor ação fitotóxica.

Quanto ao cádmio, as concentrações nas raízes e folhas também foram elevadas e semelhantes nos solos LVA e RU, aumentando com a dose aplicada e sendo, em geral, maiores nas plantas desenvolvidas no solo PVA (Figura 5). A redução da matéria seca das plantas nesse solo também caracteriza efeito de fitotoxicidade (Figura 2).

A maior dose do resíduo aplicado às plantas de arroz desenvolvidas no solo PVA, acumulou cádmio em conteúdo duas vezes superior ao considerado fitotóxico (Oliveira et al., 2005). Neste solo, nos tratamentos referentes às menores doses do resíduo o baixo teor de zinco foi 8 vezes superior ao do solo RU, o que deve ter contribuído para o aumento da absorção de cádmio pelas raízes, situação que indica competição entre o zinco e o cádmio.

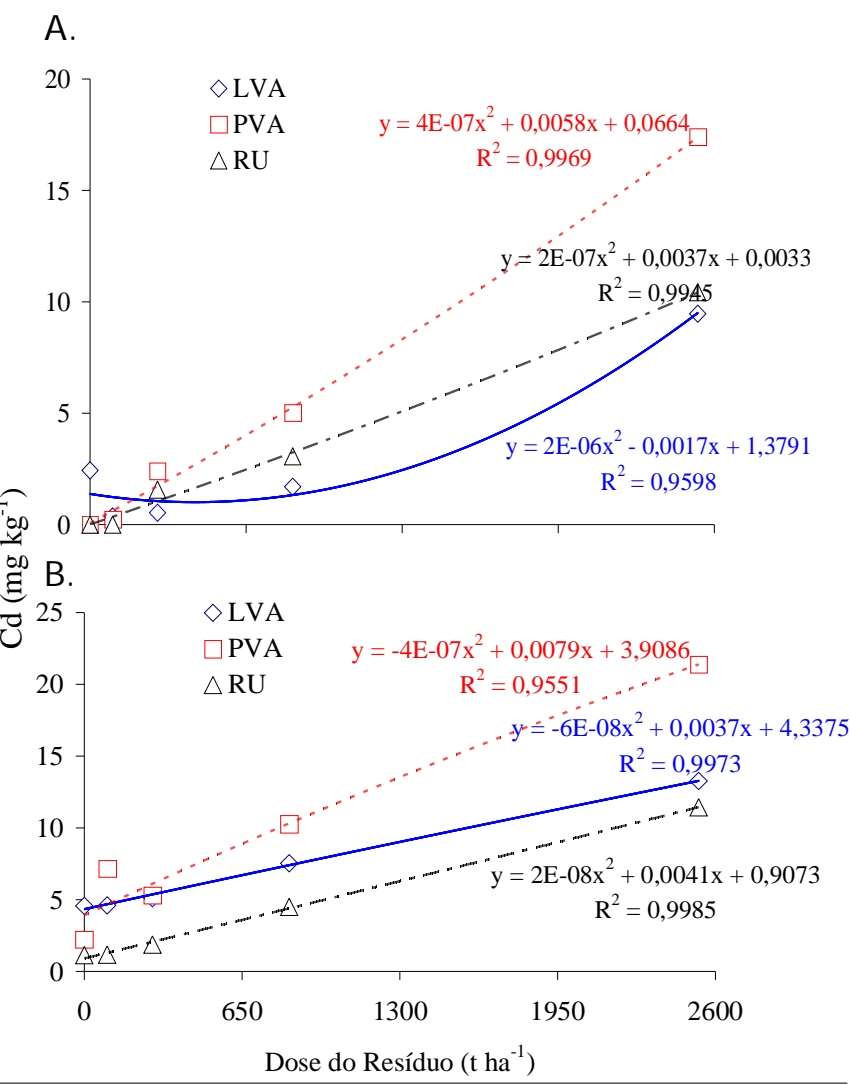

Figura 5. Concentração de cádmio na raiz (A) e parte aérea (B) em plantas de arroz cultivadas nos solos LVA; PVA e RU tratados com resíduo siderúrgico

Concentrações elevadas de $\mathrm{Ca}^{2+} \mathrm{e}_{2} \mathrm{PO}_{4}$, como observadas nos solos RU e LVA (Tabela 1), conforme Alloway (1995) e Oliveira et al. (2005), podem interagir com o cádmio, de forma a reduzirem suas atividades nas plantas. Para Alloway (1995), há competição de cálcio com o cádmio reduzindo a absorção deste último pelas plantas. A absorção de cádmio pelas plantas de arroz foi semelhante nos três solos estudados (Figura 3).

Apresentam se, na Tabela 4, os coeficientes de correlação entre quantidades extraídas com DTPA de zinco, cádmio e chumbo e as concentrações desses elementos nas raízes e parte aérea das plantas. Verificam se correlações elevadas e significativas entre as quantidades extraídas com DTPA com as quantidades acumuladas desses três elementos em plantas de arroz e com as concentrações nas raízes e parte aérea, demonstrando que tal extrator pode ser utilizado para avaliar

Tabela 4. Coeficientes de correlação de Pearson das correlações entre zinco, cádmio e chumbo extraíveis com DTPA e as concentrações nas raízes, fol has e as quantidades acumuladas nas plantas de arroz

\begin{tabular}{cccc}
\hline \multirow{2}{*}{ Correlações } & \multicolumn{3}{c}{ Coeficiente de Correlação de } \\
\cline { 2 - 4 } & Zearson $(\mathbf{r})$ \\
\hline Conc. Folhas x Extraído com DTPA & $0,61^{*}$ & $0,88^{* *}$ & $0,92^{* *}$ \\
Conc. Rázes x Extraído com DTPA & $0,82^{* *}$ & $0,95^{* *}$ & $0,95^{* *}$ \\
Acumulado na planta x Extraído com DTPA & $0,85^{* *}$ & $0,89 * *$ & $0,92^{* *}$ \\
\hline
\end{tabular}

*significativo a nível de $5 \%$ pelo teste Tuckey; ** significativo ao nível de $1 \%$ pelo teste Tuckey 
a biodisponibilidade desses três metais em solos cultivados com arroz. Correlações elevadas e significativas entre concentrações de zinco, cádmio e chumbo extraídas com DTPA e concentrações em plantas, têm sido observadas em vários trabalhos (Bataglia \& Raij, 1989; Paula et al., 1991; Mcgrath, 1996; Qian et al., 1996; Amaral Sobrinho et al., 2009).

\section{CONCLUSÕES}

1. O resíduo utilizado foi eficiente em disponibilizar zinco à cultura de arroz em solos com pH superior a 5,5.

2. O acúmulo de zinco e de chumbo foi maior nas raízes enquanto o cádmio se concentrou mais na parte aérea das plantas.

3. As altas concentrações de chumbo e cádmio no resíduo impossibilitam sua utilização como fonte de zinco ao arroz.

4. As elevadas correlações entre as concentrações de zinco, cádmio e chumbo extraídas dos solos com DTPA e as acumuladas nas plantas indicam viabilidade desse extrator para avaliação da biodisponibilidade desses três metais em solos cultivados com arroz.

\section{LITERATURA CITADA}

ABNT - Associação Brasileira de Normas Técnicas. NBR 10004: Classificação de resíduos. Rio de Janeiro: ABNT, 2004. 71p.

Accioly, A. M. A.; Siqueira, J. O.; Curi.N.; Moreira, F. M. S. Lime amelioration of zinc and cadmium toxicities for Eucalyptus camaldulensis seedlings cultivated in contaminated soil. Revista Brasileira Ciência do Solo, v.28, p.775 783, 2004.

Alloway, B. J. Heavy metals in soils. Second edition, London: Blackie A. \& P. 1995. 386p.

Amaral Sobrinho, N. M. B.; Lã, O. R; Barra, C. M. Química dos metais pesados no solo. In: Química e Mineralogia do Solo. 01.Viçosa: Sociedade Brasileira de Ciência do Solo, 2009. v.2. 685p.

Andrade, A. F. M. de; Amaral Sobrinho, N. M. B.; Magalhães, M. O. L.; Nascimento, V. S. do; Mazur, N. Zinco, chumbo e cádmio em plantas de arroz (Oriza sativa L.) cultivadas em solo após adição de resíduo siderúrgico. Ciência Rural, v.38, p.229 233, 2008.

Banat, K. M.; Howari, F. M.; Al Hamad, A. A. Heavy metals in urban soils of central Jordan: should we worry about their environmental risks. Environmental Research, v.97, p.258-273, 2005.

Barbosa Filho, M. P.; Dynia, J. F.; Zimmermann, F. J. P. Resposta do arroz de sequeiro ao zinco e ao cobre com efeito residual para o milho. Revista Brasileira de Ciência do Solo, v.14, p.333 338, 1990.

Barbosa Filho, M. P.; Fageria, N. K.; Silva, O. F.; Barbosa, A. M. Interações entre calagem e zinco na absorção de nutrientes e produção de arroz de sequeiro em casa de vegetação. Revista Brasileira de Ciência do Solo, v.16, p.355 360. 1992.

Basta, N. T.; Mcgowen, S. L. Evaluation of chemical immobilization treatments for reducing heavy metal transport in a smelter contaminated soil. Environment. Pollution, v.127, p.73-82, 2004.
Bataglia, O. C.; Raij, B. van. Eficiência de extratores de micronutrientes na análise de solo, Revista Brasileira Ciência do Solo, v.13, p.205-212, 1989.

Bonnecarrère, R. A. G.; Londero, F. A. A.; Santos, O.; Schmidt, D.; Pilau, F. G.; Manfron, P. A.; Dourado Neto, D. Resposta de genótipos de arroz irrigado à aplicação de zinco. Revista da Faculdade de Zootecnia, Veterinária e Agronomia, v.10, p.214 222, 2004.

Borges, M. R.; Coutinho E. L. M. Metais pesados do solo após aplicação de biossólido. II - Disponibilidade. Revista Brasileira de Ciência do Solo, v.28, p.557-568, 2004.

Carneiro, M. A. C.; Siqueira, J. O.; Moreira, F. M. S. Behavior of herbaceous species in soil mixes with different degree of contamination with heavy metal. Pesquisa Agropecuária Brasileira, v.37, p.1629 1638, 2002.

Castaldi, P.; Melis, P. Growth and yield characteristics and heavy metals content on tomatoes grown in different growing media. Communications in Soil Science and Plant Analysis, v.35, p.85-98, 2004.

Castaldi, P.; Santona, L.; Melis, P. Heavy metal immobilization by chemical amendments in a polluted soil and influence on white lupin growth. Chemosphere, v.60, p.365-371, 2005.

EMBRAPA - Empresa Brasileira de Pesquisa Agropecuária. Manual de métodos de análises de solos. 2.ed. Rio de Janeiro: Embrapa CNPS, 1997. 214p.

Euclydes, R. F. Manual de utilização do programa SAEG (Sistema para análises estatísticas e genéricas). Viçosa: Imprensa Universitária, 1983. 59p.

Fadigas, F.; Amaral Sobrinho, N. M. B.; Mazur, N.; Anjos, L. H.; Freixo, A. A. Estimation of reference values for cadmium, cobalt, chromium, copper, lead and zinc in brasilian soils. Communications in Soil Science and Plant Analysis, v.37, p.945 959, 2006.

Fageria, N. K. Níveis adequados e tóxicos de zinco na produção de arroz, feijão, milho, soja e trigo em solo de Cerrado. Revista Brasileira de Engenharia Agrícola e Ambiental, v.4, n.3, p.390 395, 2000.

Gichner, T.; Patková, Z.; Száková J., Demnerová, K. Toxicity and DNA damage in tobacco and potato plants growing on soil polluted with heavy metals. Ecotoxicology. Environment Safe, v.65, p.420-426, 2006.

Gupta, A. K.; Sinha, S. Phytoextraction capacity of the plants growing on tannery sludge dumping sites, Bioresource. Technology, v.98, p.1788-1794, 2007.

IBS - Instituto Brasileiro de Siderurgia. http://www.ibs.org.br/ estatisticas2.asp. 22 Abr. 2006.

IISI - International Iron and Steel Institute. The management of steel plant ferruginous by products. Brussels: IISI, 1994. 50p.

Lindsay, W. L.; Norwell, W. A. Development of a DTPA test zinc, iron, manganese and copper. Soil Science Society American Proceddings, v.42, p.421 428, 1978.

Lombi, E.; Zhao, F. J.; Zhang, G.; Sun, B.; Fitz, W.; Zhang, H.; Mcgrath, S. P. In situ fixation of metals in soilusing bauxite residue: Chemical assessment. Environment Pollution, v.118, p.435-443, 2002.

Mcgrath, D. Application of single and sequential extraction procedures to polluted and unpolluted soils. The Science of the Total Environment, v.178, p.37-44, 1996. 
Oliveira, C.; Amaral Sobrinho, N. M. B.; Marques, V. S.; Mazur, N. Efeitos da aplicação do lodo de esgoto enriquecido com cádmio e zinco na cultura do arroz. Revista Brasileira de Ciência do Solo, v.29, n.1, p.109-116, 2005.

Paula, M. B.; Carvalho, J. G.; Nogueira, F. D.; Mesquita, H. A. Curva de resposta e avaliação de extratores para zinco disponível em solos hidromórficos e aluviais sob arroz inundado. Revista Brasileira de Ciência do Solo, v.15, p.49-55, 1991.

Pavlíková, D.; Pavlík, M.; Staszková, L.; Motyka, V.; Száková, J.; Tlustoš, P.; Balík, J. Glutamate kinase as a potential biomarker of heavy metal stress in plants Ecotoxicology and Environmental Safety, v.70, p.223 230, 2008.
Qian, J.; Shan, X.; Wang, Z.; Tu, Q. Distribution and plant availability of heavy metals in different particle size fractions of soil, The Science of the Total Environment, v.186, p.131-141, 1996.

Santos, F. S. dos; Hernandezallica, J.; Becerril, J. M.; Amaral Sobrinho, N. M. B., Mazur, N.; Garbisu, C. Chelate induced phytoextraction of metal polluted soils with brachiaria decumbens. Chemosphere, v.65, p.43 50, 2006.

Sharma, P.; Dubey, R. S. Lead toxicity in plants. Brazilian Journal of Plant Physiology, v.17, n.1, p.35-52, 2005.

Sposito, G. The chemistry of soils, second edition. New York: Oxford University Press. 2008. 321p.

Tedesco, M. J.; Gianello, C.; Bissani, C. A.; Bohnen, H.; Volkweiss, S. J. Análise de solo, plantas e outros materiais, 2.ed. Porto Alegre: UFRGS, 1995. 174p. Boletim Técnico, 5. 